\title{
Multiple myeloma with concurrent immune thrombocytopenic purpura
}

\author{
Humaira Sarfraz ${ }^{1,}$, Kartik Anand ${ }^{2,}$, Shujuan Liu ${ }^{3}$ and Shilpan Shah ${ }^{2}$ \\ ${ }^{1}$ Department of Internal Medicine, Houston Methodist, Houston, TX 77030, USA \\ ${ }^{2}$ Houston Methodist Cancer Center/Weill Cornell Medicine, Houston, TX 77030, USA \\ ${ }^{3}$ Department of Pathology, Houston Methodist, Houston, TX 77030, USA \\ ${ }^{*}$ Equal contribution
}

\begin{abstract}
Multiple myeloma ( $\mathrm{MM}$ ) is the second most common haematological malignancy in the USA. MM has been linked to various autoimmune disorders in many studies; one systemic review even suggested an increased risk of $\mathrm{MM}$ among patients with autoimmune disorders. $\mathrm{MM}$ is associated with many haematological, rheumatologic and neurological conditions. A few case reports suggest that $\mathrm{MM}$ can be associated with immune thrombocytopenic purpura (ITP), although this is rare. We present a case of MM with concurrent ITP which was refractory of steroids and intravenous immunoglobulin but had a response with anti-neoplastic therapy for MM. We also review all the cases of ITP with MM described in the literature. If conventional treatment for ITP associated with MM fails to improve platelet count, anti-neoplastic therapy for MM should be considered.
\end{abstract}

Keywords: multiple myeloma, ITP, thrombocytopenia, auto immune disorder, immunoglobulin

\section{Introduction}

Multiple myeloma (MM) is a plasma cell disorder characterised by clonal proliferation of malignant cells in the bone marrow with monoclonal protein in the serum and/or urine and is associated with end-organ damage including anaemia, hypercalcemia, renal dysfunction and bone disease [1]. $\mathrm{MM}$ is the second most common haematological malignancy with an incidence of $6.2 / 100,000$ [2]. MM at presentation can be symptomatic or asymptomatic; for diagnosis, at least $>10 \%$ clonal bone marrow plasma cells plus $\geq 1$ multiple myeloma defining events are required [3]. Aetiology of MM remains unknown; some of the risk factors are advanced age, family history, male gender and environmental factors [4]. Several studies suggest a link between autoimmune disorders and MM, one systemic review suggested patients with autoimmune disease are at high risk for development of MM [5]. MM is associated with many haematological, rheumatologic and neurological conditions [6]. A few case reports suggest that rarely $\mathrm{MM}$ can be associated with immune thrombocytopenic purpura (ITP) [7]. The likely mechanisms, which may explain the correlation between MM and ITP, include that autoimmune conditions may lead to chronic B cell activation and development of MM. However, MM itself is also associated with the development of autoimmune phenomena. Third, thrombocytopenia may occur as a result of certain drugs used for treatment of MM. Most cases of ITP associated
Correspondence to: Shilpan Shah Email: sshah2@houstonmethodist.org

ecancer $2020,14: 1012$

https://doi.org/10.3332/ecancer.2020.1012

Published: $20 / 02 / 2020$

Received: 07/09/2019

Publication costs for this article were supported by ecancer (UK Charity number 1176307).

Copyright: (c) the authors; licensee ecancermedicalscience. This is an Open Access article distributed under the terms of the Creative Commons Attribution License (http:// creativecommons.org/licenses/by/3.0), which permits unrestricted use, distribution, and reproduction in any medium, provided the original work is properly cited. 
with MM respond to steroids and intravenous immunoglobulins (IVIg) [7]. Here, we present a case of MM with concurrent ITP which was refractory to corticosteroids and IVIg and had response to anti-neoplastic therapy for MM.

\section{Case presentation}

A 60-year-old male with a past medical history of bipolar disorder and schizophrenia on olanzapine presented to the hospital with generalised weakness and weight loss for the past 2 months. His physical exam was unremarkable for any petechiae, bleeding, bruises, hepatosplenomegaly or evidence of lymphadenopathy. Laboratory examination showed haemoglobin of $5.9 \mathrm{~g} / \mathrm{dL}$, WBC $2.88 \mathrm{k} / \mu \mathrm{L}$ with normal differential, platelet count of $1 \mathrm{k} / \mu \mathrm{L}$, creatinine $1.1 \mathrm{mg} / \mathrm{dL}$, calcium $8.6 \mathrm{mg} / \mathrm{dL}$, albumin $2.7 \mathrm{~g} / \mathrm{dL}$ and total protein $7.6 \mathrm{~g} / \mathrm{dL}$. Prothrombin was within normal limits (WNL), and activated partial thromboplastin time (PTT) was elevated at 42.3 seconds. Further work regarding the elevation of PTT revealed the presence of lupus anticoagulant. The D-dimer level was elevated at $2.9 \mu \mathrm{g} / \mathrm{mL}$, and fibrinogen was elevated as well at $463 \mathrm{mg} / \mathrm{dL}$. Haptoglobin was WNL at $189 \mathrm{mg} / \mathrm{dL}$, LDH was elevated at $506 \mathrm{U} / \mathrm{L}$ and reticulocyte index was low at 2 with no spherocytosis or schistocytes on peripheral smear exam which ruled out haemolysis. Immunoglobin quantification showed increased IgG at $2,157 \mathrm{mg} / \mathrm{dL}$, IgA WNL at $338 \mathrm{mg} / \mathrm{dL}$ and decreased $\operatorname{lgM}$ at $<25 \mathrm{mg} / \mathrm{dL}$. Serum and urine protein electrophoresis with immunofixation showed the presence of IgG lambda paraproteinemia at a concentration of 0.8 and $0.6 \mathrm{~g} / \mathrm{dL}$, respectively. ESR was found to be elevated at $55 \mathrm{~mm} / 1 \mathrm{st}$ hour and beta-2 microglobulin was elevated at $4.1 \mathrm{mg} / \mathrm{L}$. The patient was transfused packed red blood cells with an appropriate rise in haemoglobin, but there was no rise in platelet count checked 1 hour after platelet transfusion indicating peripheral destruction. Bone marrow biopsy was performed which showed normocellular marrow with $30 \%$ lambda restricted plasma cells (Figure $1 \mathrm{~A}-\mathrm{C}$ ) and focal megakaryocytic hyperplasia, staining positive by CD61 (Figure 1D-E). Congo red staining for amyloid was negative. Skeletal survey showed no lytic lesions. Work up done to rule out secondary causes of thrombocytopenia, including HIV, hepatitis $\mathrm{C}$ virus, rheumatological workup with anti-nuclear antibody and imaging to detect splenomegaly, was unremarkable. Hence, with all the work described earlier, a diagnosis of concurrent ITP and MM was established. This patient satisfied the criteria for MM due to the presence of $>10 \%$ clonal plasma cells in the bone marrow along with anaemia [3]. An initial trial for ITP treatment with IVIg $1 \mathrm{~g} / \mathrm{kg}$ for 2 days and dexamethasone $40 \mathrm{mg}$ daily for 4 days did not lead to an increase in platelet count. Given his refractory thrombocytopenia and concurrent multiple myeloma, he was subsequently started on cyclophosphamide, bortezomib, dexamethasone (CyBorD). On day 6 of cycle 1, a rise in platelet count to $29 \mathrm{k} / \mu \mathrm{L}$ was noted. Subsequent days thereafter, the platelet count continued to increase and peaked at $171 \mathrm{k} / \mu \mathrm{L}$ before the start of his next cycle of chemotherapy. From a multiple myeloma standpoint, there was a decrease in paraprotein load from 0.8 to $0.3 \mathrm{~g} / \mathrm{dL}$. He recently received his cycle 2 of induction chemotherapy with a future plan to repeat a bone marrow biopsy and move on to high dose chemotherapy followed by stem cell rescue.
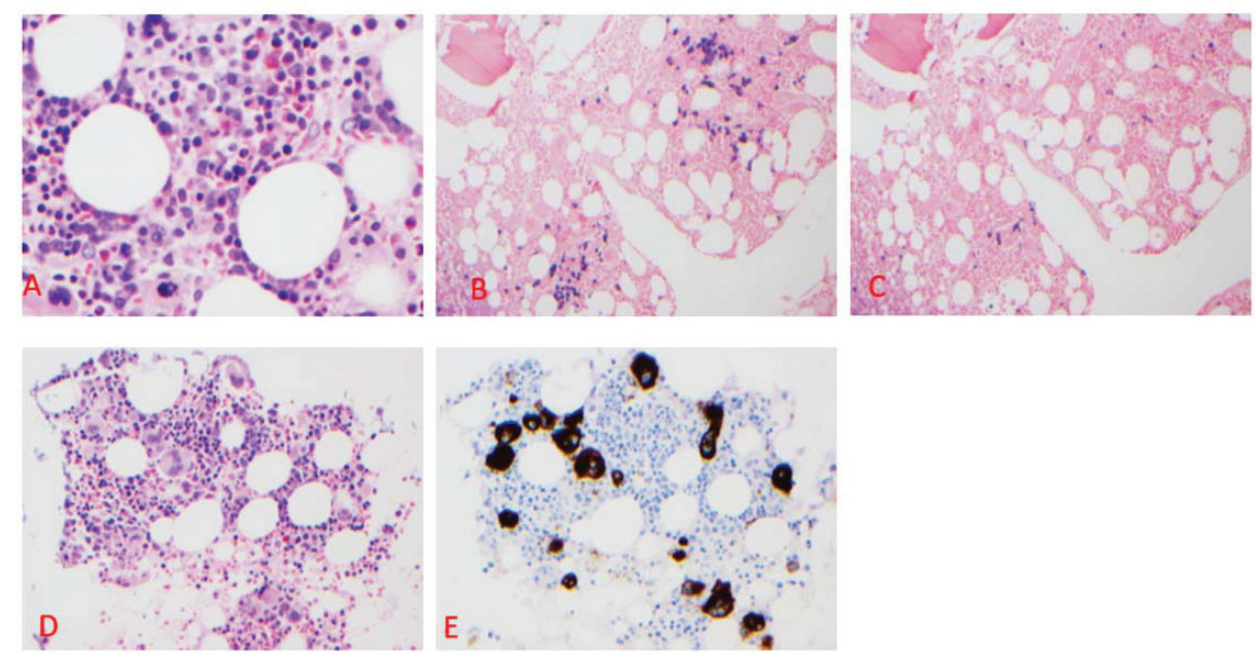

Figure 1. Clustering of lambda-light chain restricted plasma cells on Bone marrow biopsy section (A-C). A. HE $\times 200$; B. Lambda light chain ISH x100; C. Lambda light chain ISH x100. D. Focal loose clustering of megakaryocytes. A HE $\times 200$; E CD61 immunohistochemical stain $\times 200$. 


\section{Discussion}

Here, we describe a case of concurrent immune thrombocytopenic purpura with multiple myeloma which was refractory to treatment with pulse dexamethasone and IVIg but responded to treatment with chemotherapy for Multiple Myeloma with CyBorD. While thrombocytopenia may be seen with multiple myeloma commonly, ITP has rarely been encountered as an association with multiple myeloma. In most cases, thrombocytopenia results from chemotherapy during multiple myeloma treatment or marrow infiltration by the plasma cells. In our case, the absence of an increase in platelet count with platelet transfusion indicated a destructive aetiology for thrombocytopenia. Moreover, the absence of secondary causes and megakaryocytes noted on bone marrow exam confirmed diagnosis of ITP. To date, 11 cases of ITP associated with MM have been reported (Table 1), comprising of 7 males and 4 women. $M$ proteins in all patients were of IgG type. Four cases $(1,6,9,10)$ were diagnosed with ITP after receiving chemotherapy for MM, while three cases of ITP $(4,5,11)$ were diagnosed before MM. As per the literature review, there are only three cases $(3,7,8)$ of Multiple Myeloma and ITP being diagnosed concurrently $(2,4,5)$. The age spectrum of the previous cases described range from 49 to 78 years. In the case series by Gupta et al ], their patient with concurrent ITP and MM, thrombocytopenia responded to treatment with IVIg and was subsequently started on chemotherapy with VAD for MM treatment. In the case report by Tabata et al [9], initially, the patient was diagnosed with MM with mild thrombocytopenia noted with increased megakaryocytes in the bone marrow. He was treated for $\mathrm{MM}$ with melphalan and prednisone but could not receive subsequent rounds of chemotherapy due to severe neutropenic infections. It was observed that with the progression of MM, platelet count continued to decrease while the megakaryocyte concentration was preserved indicating that there could potentially be an association between MM severity and thrombocytopenia which was demonstrated by the rise in platelet associated antibody. The platelet count in that case responded to cepharanthine (natural alkaloid) most likely associated with decreased cytokine production. In the case described by Yao et al, immunosuppression for ITP was linked to MM. For cases in which MM was diagnosed before ITP $(1,6,9,10)$, it is likely that MM led to certain autoimmune sequelae resulting ITP. In such cases, medication induced effects would also need to be considered. On the other hand, when MM follows ITP diagnosis $(4,5,11)$, most likely mechanism implicated is chronic B-cell activation. While these cases may allude to the cause of an association between MM and ITP, it is still difficult to ascertain the exact mechanism given paucity of evidence and heterogeneity of disease.

In our case, there was a lack of response to IVIg and dexamethasone to ITP but there was a remarkable response of thrombocytopenia to treatment with CyBorD. While bortezomib has been found to have a good response in MM, bortezomib itself is implicated in causing thrombocytopenia in some cases too. The rise in platelets seen in our patient with concurrent ITP raises the possibility that manifestation of ITP is perhaps caused by MM itself and the treatment of MM reciprocally leads to its resolution [10, 11].

Table 1. Cases of ITP with MM described in the literature till date excluding the current case.

\begin{tabular}{|c|c|c|c|c|c|c|c|c|}
\hline Case & Reference & Age/Gender & $\begin{array}{l}\text { M protein type } \\
\text { at diagnosis }\end{array}$ & $\begin{array}{l}\text { M protein } \\
\text { conc }(\mathrm{g} / \mathrm{dL})\end{array}$ & $\begin{array}{c}\text { Platelet } \\
10^{9} / \mathrm{L}\end{array}$ & $\begin{array}{c}\text { ITP } \\
\text { Diagnosis timing }\end{array}$ & $\begin{array}{c}\text { ITP } \\
\text { Management }\end{array}$ & $\begin{array}{c}\text { Alive/Cause o } \\
\text { death }\end{array}$ \\
\hline 1 & Verdirame et al [12] & $67 \mathrm{y} / \mathrm{F}$ & IgG/lambda & 2.4 & 10 & After MM Tx & Prednisone, splenectomy & Alive \\
\hline 2 & Verdirame et al [12] & $55 \mathrm{y} / \mathrm{M}$ & IgG/kappa & 3.4 & 48 & During MM Tx & Prednisone, splenectomy & Alive \\
\hline 3 & Gupta et al [8] & $49 \mathrm{y} / \mathrm{M}$ & IgG/lambda & 4.0 & 21 & At MM Dx & IVIg, VAD & Sepsis \\
\hline 4 & Gupta et al [8] & $36 \mathrm{y} / \mathrm{M}$ & IgG/kappa & 11.9 & 5 & Before MM Dx & $\begin{array}{l}\text { Prednisone, IVIg, splenec- } \\
\text { tomy, VAD }\end{array}$ & Sepsis \\
\hline 5 & Gupta et al [8] & $45 \mathrm{y} / \mathrm{M}$ & IgG/lambda & 6.1 & 20 & Before MM Dx & Steroid, IVIg, splenectomy & Alive \\
\hline 6 & Falco et al [13] & $45 \mathrm{y} / \mathrm{M}$ & IgG/kappa & 1.8 & $<10$ & After MM Tx & Prednisone, IVIg & N/A \\
\hline 7 & Siniscalchi et al [14] & $67 \mathrm{y} / \mathrm{F}$ & IgG/kappa & 2.6 & 3 & At MM Dx & Prednisone, IVIg, Rituximab & Alive \\
\hline 8 & Tabata et al [9] & $78 \mathrm{y} / \mathrm{M}$ & IgG/kappa & 4.18 & 17 & At MM Dx & $\begin{array}{l}\text { Melphalan, Prednisone, } \\
\text { Cepharanthine }\end{array}$ & $\begin{array}{l}\text { Unknown cause } \\
\text { of death }\end{array}$ \\
\hline 9 & Faller et al [7] & $66 \mathrm{y} / \mathrm{M}$ & IgG/kappa & 1.00 & $<10$ & After MM Tx & IVIg & Alive \\
\hline 10 & Faller et al [7] & $41 \mathrm{y} / \mathrm{F}$ & IgA/kappa & $\mathrm{N} / \mathrm{A}$ & $<10$ & After MM Tx & IVIg, Dexamethasone & Gl bleed \\
\hline 11 & Yao et al [15] & $61 \mathrm{y} / \mathrm{M}$ & IgG/kappa & N/A & 27 & Before MM Dx & $\begin{array}{l}\text { Refractory ITP; Prednisone, } \\
\text { IVlg, Danazol, IFN, AZT }\end{array}$ & Alive \\
\hline
\end{tabular}


The pathogenesis of ITP with MM is poorly understood. It has been hypothesised that immune alterations promote the generation of autoimmune platelet antibodies [8]. This case presentation describes a rare autoimmune manifestation of MM (ITP) and highlights that the treatment of MM with combination chemotherapy can lead to resolution of ITP refractory to IVIg and corticosteroids treatment.

\section{Conclusion}

In conclusion, we discuss a rare case of MM complicated by concurrent ITP. In contrast to most common associations of ITP and MM which usually respond to IVIg, steroids or splenectomy, ours was a unique case where administration of chemotherapy (CyBorD) resulted in normalisation of platelet count. This response suggests the implication of abnormal immune mechanisms in ITP associated with MM.

\section{Conflicts of interest}

None.

\section{Funding}

The authors received no specific funding for this work.

\section{References}

1. Palumbo A and Anderson K (2011) Multiple myeloma N Engl J Med 364(11) 1046-1060 https://doi.org/10.1056/NEJMra1011442 PMID: 21410373

2. Siegel RL, Miller KD, and Jemal A (2016) Cancer statistics CA CancerJ Clin 66(1) 7-30 https://doi.org/10.3322/caac.21332 PMID: 26742998

3. Rajkumar SV, Dimopoulos MA, and Palumbo A, et al (2014) International myeloma working group updated criteria for the diagnosis of multiple myeloma Lancet Oncol 15(12) e538-e548 https://doi.org/10.1016/S1470-2045(14)70442-5 PMID: 25439696

4. Alexander DD, Mink PJ, and Adami HO, et al (2007) Multiple myeloma: a review of the epidemiologic literature Int J Cancer 120(12) 40-61 https://doi.org/10.1002/ijc.22718 PMID: 17405120

5. McShane CM, Murray LJ, and Landgren O, et al (2014) Prior autoimmune disease and risk of monoclonal gammopathy of undetermined significance and multiple myeloma: a systematic review Cancer Epidemiol Biomarkers Prev 23(2) 332-342 https://doi.org/10.1158/10559965.EPI-13-0695 PMID: 24451437

6. Shimanovsky A, Alvarez Argote J, and Murali S, et al (2016) Autoimmune manifestations in patients with multiple myeloma and monoclonal gammopathy of undetermined significance BBA Clin 6 12-18 https://doi.org/10.1016/j.bbacli.2016.05.004 PMID: 27331023 PMCID: 4900299

7. Faller E, Chapman L, and Enright $\mathrm{H}$, et al (2016) Immune thrombocytopenia purpura associated with multiple myeloma Ann Hematol 95(8) 1371-1372 https://doi.org/10.1007/s00277-016-2694-y PMID: 27178045

8. Gupta V, Hegde UM, and Parameswaran R, et al (2000) Multiple myeloma and immune thrombocytopenia Clin Lab Haematol 22(4) 239-242 https://doi.org/10.1046/j.1365-2257.2000.00125.x PMID: 11012639

9. Tabata R, Tabata C, and Tazoh A, et al (2012) Low dose cepharanthine ameliorates immune thrombocytopenic purpura associated with multiple myeloma Int Immunopharmacol 13(3) 242-244 https://doi.org/10.1016/j.intimp.2012.04.015 PMID: 22561120 
10. Richardson PG, Sonneveld P, and Schuster MW, et al (2005) Bortezomib or high-dose dexamethasone for relapsed multiple myeloma $\mathrm{N}$ Engl J Med 352(24) 2487-2498 https://doi.org/10.1056/NEJMoa043445 PMID: 15958804

11. Lonial S, Waller EK, and Richardson PG, et al (2005) Risk factors and kinetics of thrombocytopenia associated with bortezomib for relapsed, refractory multiple myeloma Blood 106(12) 3777-3784 https://doi.org/10.1182/blood-2005-03-1173 PMID: 16099887 PMCID: 1895114

12. Verdirame JD, Feagler JR, and Commers JR (1985) Multiple myeloma associated with immune thrombocytopenic purpura Cancer 56(5) 1199-1200 PMID: 4040420

13. Falco P, Bertola A, and Bringhen S, et al (2004) Successful management of immune thrombocytopenic purpura with thalidomide in a patient with multiple myeloma Hematol J 5(5) 456-457 https://doi.org/10.1038/sj.thj.6200404 PMID: 15448677

14. Siniscalchi A, Stasi R, and Fratoni S, et al (2009) Management of immune thrombocytopoenia in a patient with newly-diagnosed smouldering myeloma and colorectal cancer BMJ Case Rep 2009 bcr0320091715

15. Yao H, Zhang X, and Liu J, et al (2015) Multiple myeloma developing during long-term clinical course of refractory immune thrombocytopenic purpura: a case report and review of literature Int J Clin Exp Pathol 8(11) 15429-15432 